Hydrology and Earth System Sciences, 8(3), 327-333 (2004) C EGU

\title{
Measuring rainfall to a forest canopy: an assessment of the performance of canopy level raingauges
}

\author{
M. Robinson ${ }^{1}$, S.J. Grant ${ }^{2}$ and J.A. Hudson ${ }^{1,3}$ \\ ${ }^{1}$ Centre for Ecology and Hydrology, Wallingford, Oxon, OX10 8BB, UK \\ ${ }^{2}$ Centre for Ecology and Hydrology, Bangor, University of Wales Bangor, LL57 2UP, UK \\ ${ }^{3}$ Present address: 10 Brockton Meadow, Brockton, Worthen, Shrewsbury, SY5 9QN \\ Email for corresponding author: mr@ceh.ac.uk
}

\begin{abstract}
Accurate rainfall measurements are crucial for water resource and environmental assessments but can be difficult to achieve in extensive areas of forest. This paper reviews the different techniques for measuring rainfall to a forest area and presents the results of a 5 -year experiment comparing the catches of gauges installed above a forest canopy with those of ground level gauges outside the forest. It examines the consistency of the catches between the canopy gauges, the sensitivity of the catch to the height of the gauge rim above the forest canopy, and compares the canopy gauge catches to the 'true' rainfall in ground level gauges just outside the forest. The study shows that suitably designed and maintained canopy gauges can provide consistent measures of rainfall to a forest surface that are sufficiently accurate for most purposes and offer a preferable alternative to measurements in small clearings.
\end{abstract}

Keywords: rainfall, raingauge, forest canopy, water balance, Plynlimon

\section{Introduction}

Rainfall is one of the most fundamental environmental measurements. However, it is surprisingly difficult to measure accurately. The ideal raingauge is one that catches exactly the same rain that would have fallen if the gauge had not been present. Furthermore the location of this point measurement should be representative of a larger area. It is well established that the amount of rain collected by a conventional gauge placed upon the ground is generally less than the actual rainfall at the site. The presence of the gauge distorts the air flow and generates turbulence causing the wind speed to increase over the gauge itself carrying some of the raindrops beyond the gauge and reducing its catch systematically (e.g. Rodda, 1968; Sevruk and Klemm, 1989).

Two main approaches have been adopted to reduce the effect of the gauge on windflow patterns. One is to position the rim of the gauge so that it is level with the surrounding ground, by either putting the gauge in a pit or by building a turf wall around it. The other is to alter raingauge shapes by either adding a windshield or redesigning the shape of the gauge itself (Folland, 1988; Sevruk et al. 1989; Hughes et al., 1993). The siting of the gauge also has an important bearing on the wind speeds that the gauge experiences. In general, a gauge site must not be too sheltered from the wind as this may cause it to be in a rain shadow. Similarly, if it is too exposed to the wind it may also be prone to undercatch, especially in strong winds. General guidelines for gauge location recommend that obstructions, such as buildings and trees, should not be closer to the gauge than a distance of twice their height above the gauge (Met. Office, 1982, 2001; WMO, 1994), or subtending an angle of greater than $30^{\circ}$ above the horizontal from the gauge rim. Differences in catch between UK standard gauges (rim height $30.5 \mathrm{~cm}$ ) and ground level gauges are typically $5 \%$ in lowland areas rising to as much as $15 \%$ in windy upland locations (Rodda and Smith, 1986; Price, 1999). The problems of measuring solid precipitation such as snow or hail are even greater and are not dealt with in this paper .

The inherent problems of rainfall measurement are especially acute for rainfall in forested areas: due to the 
greater aerodynamic roughness of the tall vegetation, the amount of wind turbulence will be much greater. Forestry is a major land cover; $10 \%$ of Britain, $30 \%$ of Europe and nearly $40 \%$ of the global land surface are forested. This poses particular problems for the assessment of rainfall inputs that may be crucial for water resource assessments. There is, however, little information specific to the measuring of rainfall to forested areas. For example, neither of the 'Handbooks of Hydrology' (Maidment, 1992; ASCE, 1996) deal with this topic, other than to note "Raingauge measurement is difficult in ... forests".

The traditional methods of measuring rainfall in forested areas have been to transpose rainfall measurements from outside the forest or to try to find a suitable clearing in the forest. These approaches are problematical. The interpolation of rainfall catches across a landscape is valid only in areas with low rain gradients (but this cannot be known in advance) and for relatively small forest areas. Treeless areas in large forests may be unrepresentative (e.g. mountain tops above the tree line) and so it may be necessary to look to open areas such as artificial clearings. However, unplanted areas and clearings may be subject to problems of wind turbulence unless they are quite large. For example, Geiger (1966), who measured precipitation in forest clearings of different sizes, found a strong bias due to sheltering and interception by the tree canopy. The lowest catches were recorded in the smallest clearings; when the clearing was of sufficient size for the gauge in the middle to be at a distance of 1.6-times the tree height from the forest edge, the rainfall was within a couple of percent of the rainfall in open ground. Applying this recommended minimum distance from a raingauge to the nearest obstruction would require that the clearings are excessively large, particularly if the forest is tall; for example, a $15 \mathrm{~m}$ tall forest would require a $50 \mathrm{~m}$ diameter clearing increasing to $100 \mathrm{~m}$ wide clearing in a $30 \mathrm{~m}$ tall forest.

One solution is to place a gauge on a mast or tower at a similar height to the top of the canopy (e.g. Law, 1958; Oliver, 1974; Lloyd, 1990). This method is an attractive, although not trivial solution in areas of large continuous forest since the locations can be chosen objectively rather than restricted to a few treeless areas. Such uses have been confined to specific research projects and not as a part of any operational network by a national gauging authority. The accuracy of such canopy gauges to measure precipitation inputs to the forest canopy is the subject of this paper.

This investigation addresses the following questions:

(a) Is the canopy gauge technique capable of providing consistent results? (b) Are the catches unduly sensitive to small changes in height above the forest canopy? (e.g. due to forest growth)

(c) If they can produce consistent and robust results, then how closely do their catches match those of nearby ground level gauges in adjacent moorland?

\section{Study area}

The Plynlimon catchments in mid-Wales have been studied extensively from the late 1960 s to determine the difference in water use of two upland headwater catchments under different vegetation covers. These catchments comprise the headwaters of two important UK rivers, the Severn and the Wye: the upper Severn is largely coniferous forestry and the upper Wye is under moorland (Kirby et al., 1991). At the start of the study, it was realised that to establish an accurate water balance it was essential to have a spatially dense network of gauges across both catchments. The raingauges were distributed on a stratified-random basis, whereby each catchment was divided into topographic 'domains' with particular combinations of altitude, slope and aspect ranges; these characteristics were considered $a$ priori to be the main controls on precipitation variation. For the Wye, and the unforested headwater portion of the Severn, ground-level (pit) gauges were installed, with aerodynamic anti-splash grids (BSI, 1996). Such gauges are less prone to systematic errors particularly in upland areas exposed to high winds (Rodda and Smith, 1986).

This approach was not appropriate for the Severn catchment, which is largely covered by the even-aged conifer plantations of the Hafren forest and mainly comprises Sitka spruce (Picea sitchensis). Consequently, there are few suitable unplanted sites that are large enough not to be prone to catch errors due to wind turbulence effects around the forest edge. It was decided that to get both an even areal coverage of gauges and to sample the different 'domains' it was necessary to install the gauges on towers in the forest canopy. Great care was taken in their design so that the canopy gauge measurements would be comparable with those from the ground level gauges.

The long term water balance of the Severn headwater catchments has been based on the assumption that the canopy gauges provide a satisfactory measure of rainfall input to the forest (Kirby et al., 1991) and these results have been extensively used in developing models of the water resource implications of forestry. Hudson et al. (1997) reported an apparent decline over time in the annual evaporation of the Severn catchment (measured as the residual of rainfall minus streamflow) making it desirable 
to check that the canopy gauges were still providing an accurate measure of rainfall inputs. The accuracy of rainfall measurements in forested areas is also highly pertinent to the long-standing debate of whether forests can enhance rainfall (Chang, 2002).

Clarkson (1973) compared a tulip-shaped funnel gauge installed on a 10-metre tall mast over short grass and a standard gauge with its rim at $30 \mathrm{~cm}$ over grass. He found that over a two-year period they collected almost the same rainfall. For the work at Plynlimon, tests were conducted with numerous different canopy gauge designs until a final shape was adopted. It was found that shielded gauges generally increased rather than reduced the error due to wind, and that a simple funnel gauge gave the best results compared to the catch of a ground level gauge near the base of the mast. Due to the greater air turbulence and mixing over a forest compared to over grass the impact on rainfall catch of a raingauge over forest will be less than that on a raingauge over a smooth grass surface. The roughness lengths of forests are two orders of magnitude greater than for grass ( $1 \mathrm{~m}$ for forests and $0.01-0.05 \mathrm{~m}$ for grass), which is much greater than the size of a gauge. Consequently, there is no laminar flow across the gauge for a shield to intercept so that the presence of the shield makes the gauge a bigger obstacle to the wind. Thus, Jäger (1985) compared the catches of a shielded and unshielded tower gauges with that of a standard gauge and found the unshielded gauge provided the most similar catch.

The solution adopted for the Plynlimon catchments was to install gauges on masts in the forest with their rims at or above the mean canopy-level level (Bucknell et al., 1977). In practice, this meant that the canopy gauge funnel should be as high or preferably about $1 \mathrm{~m}$ higher than the tallest tree that was reasonably near to the gauge, say within $10 \mathrm{~m}$. The type of gauge adopted was an unshielded inverted cone with a 5 -inch $(127 \mathrm{~mm})$ diameter orifice since that was found to have the best aerodynamic shape for this application. An initial analysis of the first two years of monthly mean catches of six canopy level gauges and four ground level gauges (April 1971-March 1973) found little statistical difference between the mean catch of the two types of gauge located in similar altitude, aspect or ground slope domains, except — as expected — at times of snowfall (Newson and Clarke, 1976). This, of course, does not prove conclusively that the catches of the two types of gauge are the same, as there was no direct comparison between adjacent gauges and no statistical allowance for variability within each domain. In the present study, a direct comparison was made between several canopy and ground level gauges at the same location. A cluster of canopy gauges was specially installed in order to study the variability of the canopy gauges. They were then compared with the catches of nearby ground level gauges to test for any bias. During this study, the height of the canopy gauges was altered to simulate the impact of forest growth on the relative height of the canopy gauges and investigate the sensitivity of their catch performance.

\section{Experimental design}

The chosen study area lies near the headwaters of the Hore sub-catchment in the Hafren forest. The trees were Sitka spruce planted in 1964 at a density of 3300 per hectare and at the start of the study in March 1999 were approximately 12 metres tall. The site has an existing long-term canopy gauge and had also been the location of a previous shortterm unpublished comparison between the catches of a ground level gauge and a canopy gauge over 16 months in 1978/9 when the trees were barely $5 \mathrm{~m}$ tall. In that study, the catches of the two gauges were very similar but this result may not hold for more mature forests.

The layout of the site comprises the existing gauge (X) situated at about $30 \mathrm{~m}$ from the forest edge together with three additional canopy gauges (A, B, C) installed along a line aligned with the ground slope (approximately $11^{\circ}$ ) about 55 metres from the forest edge (Fig. 1). These three gauges were 10 and 15 metres apart with the middle gauge 25 metres from the original gauge. All were installed with their rims horizontal and at a similar height above the canopy to the existing gauge by the same personnel who had been involved with the operation of the catchment canopy gauges. This experimental design enabled the effect of position on slope and distance from the forest edge to be studied separately. To provide a benchmark catch for these gauges, two ground level gauges 10 metres apart were installed 32 metres away from the forest edge, 2.7 times the tree height $\left(21^{\circ}\right.$ above horizontal from the gauge rim to the tops of the trees). This allowed for further growth of the forest during the course of the experiment without compromising the exposure of these gauges. The ground level gauges surrounded by antisplash grids were installed with their rims aligned to the local ground slope to be flush with the ground surface; their catch was multiplied by the secant of the angle that the orifice deviated from the horizontal to compensate for the smaller plan area of orifice seen by vertically falling rain to give comparable rain depths. An Automatic Weather Station approximately $500 \mathrm{~m}$ distant provided information on weather conditions, including wind run and direction.

The gauges were read at approximately two-week intervals from March 1999 to September 2003, with a four month break from February to June 2001 when Foot and Mouth Disease restrictions prevented access to the site. The weather station data confirmed that this is a windy upland site 


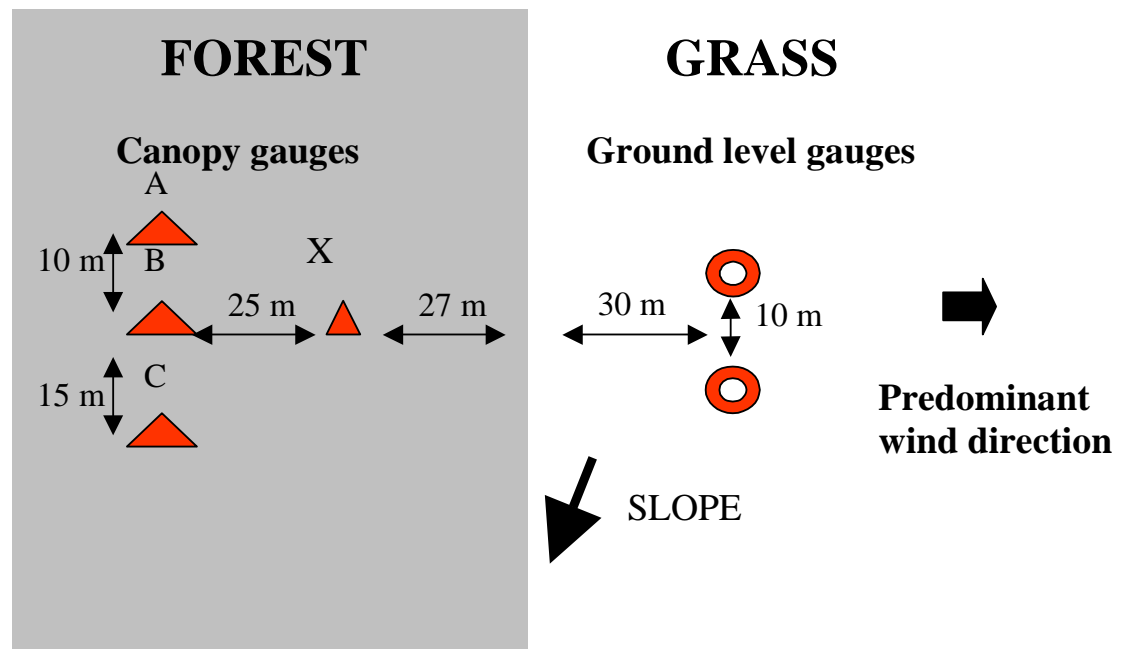

Fig. 1. Plan of the experimental site showing the raingauges used in this study

(average wind speed $4.1 \mathrm{~m} \mathrm{~s}^{-1}$, standard deviation $2.3 \mathrm{~m} \mathrm{~s}^{-1}$ ). The winds predominantly ( $47 \%$ of the time) came from the south-west, and travelled over about $500 \mathrm{~m}$ of forest before reaching the canopy gauge site.

The first part of the analysis was concerned with checking the operation of the canopy gauges - the consistency between sites and any effect of position with respect to slope or distance to forest edge and, then, the sensitivity of the catches to the position of each gauge relative to the level of the tree canopy was examined. As expected, both the canopy and ground level gauges gave unreliable measurements during snowfall, so these periods were excluded from the analyses.

\section{(A) INTERCOMPARISON OF THE CATCHES OF CANOPY GAUGES AT SAME HEIGHT}

The 9-month period from March 1999 to January 2000 provided 18 snow-free periods for study. The mean rainfall catch of the four canopy gauges over this period was $1426.5 \mathrm{~mm}$ (s.d. $29.8 \mathrm{~mm}$ or $2.1 \%$ ). Comparison plots of pairs of gauges indicated that they were behaving similarly (Fig. 2) and this was confirmed by the very high correlations between the individual canopy gauges: all of the correlation coefficients were greater than $0.997\left(\mathrm{R}^{2}=99.4 \%\right.$ variation explained) (Table 1).

The three new canopy gauges were the same distance from the forest edge, but at different positions along the ground slope. There was a small increase in catch down the slope the downslope gauge $\mathrm{C}$ recorded $3.1 \%$ greater catch than the midslope gauge $\mathrm{B}$ whilst the upslope gauge recorded 2.7\% less. However, a Student's paired two-sample t test indicated there was a less than $4 \%$ probability that difference
March 1999 - January 2000

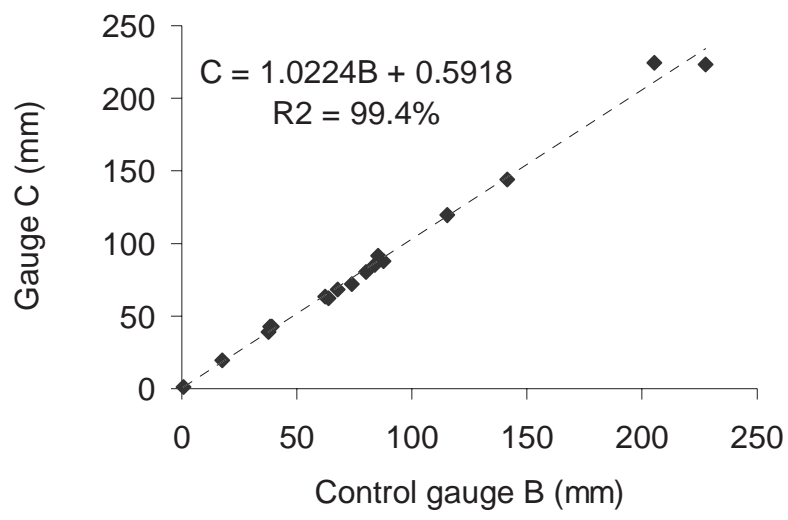

Fig. 2. Comparison of canopy gauge catches during the control period

Table 1. Correlation coefficients between pairs of canopy gauges for the control period March 99 to January 2000.

\begin{tabular}{lllll}
\hline & $\mathbf{A}$ & $\mathbf{B}$ & $\mathbf{C}$ & $\mathbf{X}$ \\
\hline $\mathbf{A}$ & 1 & & & \\
$\mathbf{B}$ & 0.9997 & 1 & & \\
$\mathbf{C}$ & 0.9973 & 0.9973 & 1 & \\
$\mathbf{X}$ & 0.9995 & 0.9992 & 0.9974 & 1 \\
\hline
\end{tabular}

between the mean values of the catches of the three new canopy gauges was statistically significant. Turning to the effect of distance from forest edge, new gauge B is at the same altitude but twice the distance from the forest edge than existing gauge $\mathrm{X}$. The period totals were within $2.3 \%$ 
of each other and the probability that their means were different was about $1 \%$.

\section{(B) EFFECT ON CANOPY GAUGE CATCH OF CHANGING GAUGE HEIGHT}

Once it had been established that the four canopy gauges yielded consistent results, in terms of both absolute totals and their variation through time, it was necessary to check on the 'robustness' of their performance. The new gauges had been installed by the same experienced staff and were set a similar level above the forest canopy. In practice, the level of the gauge rims relative to the top of the forest canopy will change over time due to growth of the trees, and the gauges need to be raised periodically. Potentially this could result in a 'saw tooth' variation in gauge height above the forest with a jump as the canopy gauge is raised periodically by up to a couple of metres followed by forest growth steadily catching up. The question then arises of the extent to which these changes might affect the gauge catch.

In January 2000, canopy gauge A was raised by $2.75 \mathrm{~m}$ and $\mathrm{C}$ was lowered by $0.4 \mathrm{~m}$. The subsequent catches were compared to unchanged gauges $\mathrm{B}$ and $\mathrm{X}$ for the period up to April 2002. With the four month break during Foot and Mouth restrictions, this provided 27 snow-free periods (Table 2). The mean rainfall for the four canopy gauges was $3839 \mathrm{~mm}$ (s.d. $97 \mathrm{~mm}$ or $2.5 \%$ ). The catch of both adjusted gauges increased slightly relative to the two control gauges (Table 2), but the correlation coefficients between the individual canopy gauges remained above 0.99 and the t-test analysis confirmed that the differences were not statistically significant. The probability of their coming from populations with different means was less than $2 \%$.

Jäger (1985) reported on 11 years of rain measurements over a Scots pine (Pinus sylvestris) forest, which included a reduction in the height of the gauge over the forest canopy due to tree growth and then the subsequent raising of the gauge by 4 metres. When the level of the gauge rim was close to the forest canopy, the catch was similar to that of a gauge over grass; raising the gauge above the forest canopy by $4 \mathrm{~m}$ reduced the catch by nearly $20 \%$. Taking the published time series data of the catch ratios and plotting them against the height of the gauge rim above the forest

Table 2. Comparison of canopy gauge catches $(\mathrm{mm})$ before and after the rim heights of $\mathrm{A}$ and $\mathrm{C}$ were altered.

\begin{tabular}{lllll}
\hline Period & $X$ & $A$ & $B$ & $C$ \\
\hline March 1999 -Jan 2000 & 1407 & 1398 & 1438 & 1483 \\
February 2000 - April 2002 & 5525 & 5788 & 5500 & 5864 \\
\hline
\end{tabular}

Jaeger - forest tower gauge

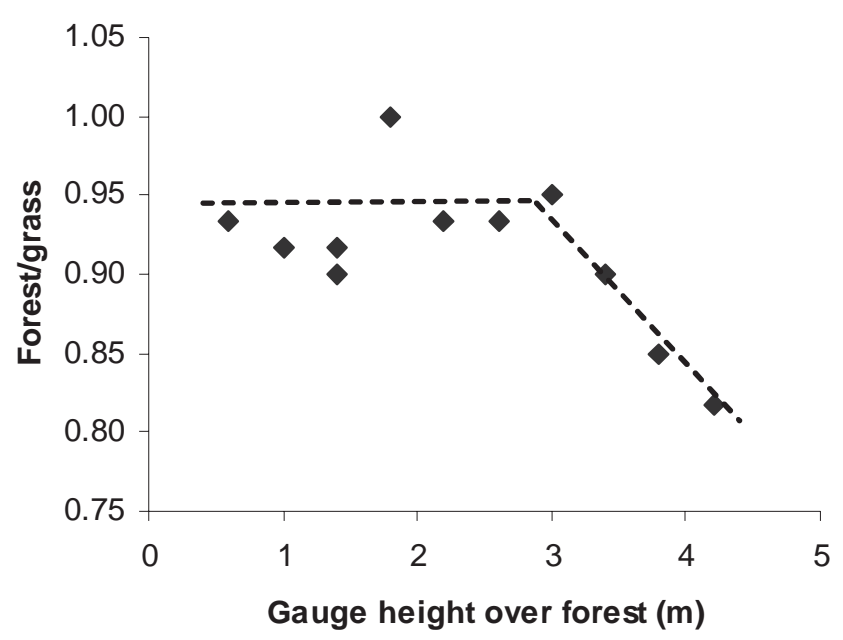

Fig. 3. Effect of canopy gauge height above the forest on its catch (based on data in Jäger, 1985).

canopy revealed that there was no systematic effect on the catch of its position in the measured range 0.5 to $3 \mathrm{~m}$ above the canopy (Fig. 3). A reduction in catch occurred only when the gauge was raised higher, and so would have been exposed to much stronger winds. This finding is consistent with a less steep logarithmic wind profile that would be expected in the first few metres over the forest due to the greater turbulence and mixing.

As an additional check on the effect of canopy gauge height on its catch, in April 2002 the two gauges were then repositioned at their original levels for a third measurement period that extended to September 2003. By the end of this period, the trees were about $0.5-1 \mathrm{~m}$ taller than at the start of the study in March 1999. This provided an additional 24 snow-free periods for study with an average rainfall catch of $2715 \mathrm{~mm}$. The totals were again similar (s.d. $43 \mathrm{~mm}$ or $1.6 \%$ ) and correlations between canopy gauges were above 0.99 . The t-test analysis confirmed that the probability of their means being different was less than $2 \%$.

The catches for the canopy gauges $\mathrm{A}$ and $\mathrm{C}$ are shown relative to control gauge $\mathrm{B}$ for the whole study encompassing the three periods of gauge height changes and approximately $10000 \mathrm{~mm}$ of rainfall (Fig. 4). Despite the changes in gauge height there is great consistency in the canopy gauge catches.

Law $(1956,1958)$ installed gauges on poles at different heights relative to the tree canopy and concluded that the gauge rims should be positioned above the canopy since gauges within the canopy were deprived of rain by the nearby branches. 


\section{Effect of height on canopy gauge A catch}

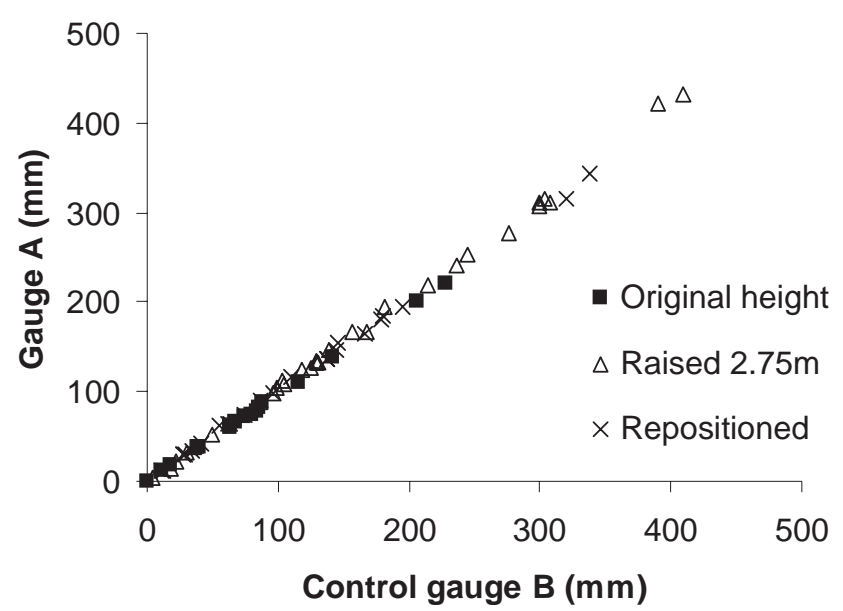

Fig. 4. Comparison of canopy gauge catches over the whole period showing the absence of effect of changing the canopy gauge rim height.

\section{(C) COMPARISON OF CANOPY AND GROUND}

LEVEL GAUGES

Now that the investigation has established that canopy gauges are capable of providing consistent results and are not unduly sensitive to their height over the forest, it is possible to make valid comparisons of their catches with ground level gauges - the most widely accepted best measure of 'true' rainfall. The pair of adjacent ground level gauges had broadly similar total catches — but with a tendency for higher catches at the upslope gauge. Over the study period, this averaged a $3.5 \%$ higher catch at the upslope ground level gauge. The t-test indicated that it could not be assumed that the two ground level gauges had the same mean values at the $10 \%$ probability level, which emphasises the need to keep any inter-canopy gauge variation in perspective.

The difference in catch between individual pairs of canopy gauges over the 5-year period of study is shown in Table 3. The differences were about $3 \%$, with no statistically significant difference between the four canopy gauges, but there was a probable real difference versus the two ground level gauges which has almost a $9 \%$ greater catch. This is similar to the difference in catch of a ground level gauge and standard gauge (Rodda and Smith, 1986). As an additional check on the variability of rain catches a standard height gauge was installed by the upslope ground level gauge in September 2002. Over the following year this recorded 9.2\% less catch than the adjacent ground level gauge.

This indicates that canopy gauges can provide estimates of rainfall inputs that are at least comparable with standard
Table 3. Ratios of the catches of canopy gauge $(\mathrm{A}, \mathrm{C})$ to the two control gauges ( $\mathrm{B}$ and $\mathrm{X}$ ) in the three different periods.

\begin{tabular}{lllllll}
\hline Period & \multicolumn{2}{c}{$\mathrm{A}$} & \multicolumn{2}{c}{$\mathrm{C}$} & $\mathrm{X}$ \\
& $B$ & $X$ & $B$ & $X$ & $B$ \\
\hline 1 & 0.972 & 0.994 & 1.017 & 1.040 & 0.978 \\
2 & 1.032 & 1.042 & 1.045 & 1.054 & 0.991 \\
3 & 1.017 & 1.035 & 1.032 & 1.057 & 0.982 \\
\hline
\end{tabular}

gauges over grass. In fact, it is possible that the catches of the ground level gauges, $30 \mathrm{~m}$ from the upwind forest edge, were affected by the change from forest to moorland (Gash, 1986) causing windflow to drop over the ground level gauges, enhancing their catch and exaggerating the apparent difference with the canopy gauges. There is a long-term ground level gauge (D1W) about $350 \mathrm{~m}$ from the forest edge at a similar altitude to the two ground level gauges used, here, and its catch over the period is within $2 \%$ of the mean of the four canopy gauges.

\section{Conclusions}

- Canopy gauges give results that are consistent with each other in terms of their high correlation coefficients

- The gauges should be positioned with their funnels above the canopy - heights up to several metres above appear to give satisfactory results without there being a notable change in the catch

- The observed canopy gauge catches did differ from those of the ground level gauges but the ground level gauges may have been sheltered by the forest upwind. The canopy gauge catches were very similar to that at another ground level gauge further downwind from the forest edge.

- Neither canopy gauges nor ground level gauges can measure snow accurately.

The findings of this study indicate that canopy gauges can provide a practical solution for rainfall measurements in forest areas where conventional gauges sited on the ground cannot be used. There is great consistency in their relative catches and their totals (excluding snow periods) are comparable with those of nearby ground level gauges. Care must be taken to ensure that they are not submerged by growth of the trees, but they appear to be insensitive to differences in the height of the rim of the funnel over the vegetation, at least for the first few metres.

When viewed in the context of the catchment water 
balance, where evaporative losses are calculated as the difference between rainfall and streamflow, care needs to be taken in the long-term operation of these gauges to raise the gauges regularly to keep them above the canopy level to prevent the systematic underestimation of the rainfall inputs to the forest. This forms part of a separate research study where evaporation fluxes are being estimated independently from a forest canopy using micrometeorological instruments (van der Tol et al., 2003).

\section{Acknowledgements}

The authors acknowledge the contribution of colleagues over many years who designed, installed, maintained, read and analysed the network of raingauges in the Wye and Severn catchments. Of these, particular thanks should go to Phil Hill and Alun Hughes who installed and initially ran the raingauge array described in this paper. Anna Newson was responsible for early scientific analyses of the data. John Rodda provided background information to the original design of the canopy gauge network at Plynlimon.

\section{References}

ASCE, 1996. Hydrology Handbook. Amer. Soc. Civ. Eng.. New York, USA. 784pp.

BSI, 1996 Guide to the Acquisition and Management of Meteorological Precipitation Data. BS 7843. British Standards Institution, London, UK.

Bucknell, A.J., Hill, P.J. and Newson, A.J., 1977. Two research raingauge procedures from the Plynlimon catchments. In: Selected measurement techniques in use at Plynlimon experimental catchments, M.D. Newson (Ed.). Institute of Hydrology Report 43. Wallingford, UK. 41pp

Chang, M., 2002. Forest hydrology. CRC Press. London, UK. $373 \mathrm{pp}$.

Clarkson, L.S., 1973. The performance of a mast-top raingauge in the field. Meteorol. Mag., 102, 82-85.

Folland, C.K., 1988. Numerical models of the raingauge exposure problem, field experiments and an improved collector design. Quart. J. Roy. Meteorol. Soc., 114, 1485-1516.

Gash, J.H.C., 1986. Observations of turbulence downwind of a forest-heath interface. Bound-lay Meteorol., 36, 227-237.

Geiger, R., 1966. The Climate near the Ground. Harvard University Press. Cambridge, USA. 611pp.

Hudson, J.A., Crane, S.B. and Blackie, J.R., 1997.The Plynlimon water balance 1969-95: the impact of forest and moorland vegetation on evaporation and streamflow in upland catchments. Hydrol. Earth Syst. Sci., 1, 409-427.
Hughes, C., Strangeways, I.C. and Roberts, A.M. 1993. Field evaluation of two aerodynamic raingauges. Weather, 48, 6671.

Jäger, L., 1985. Eleven years of precipitation measurements above a small pole wood pine stand. Workshop on Correction of Precipitation Measurements. Zurich, Switzerland. 101-103.

Kirby, C., Newson, M.D. and Gilman, K., 1991. Plynlimon Research: The first two decades. Inst. Hydrol. Report 109. Wallingford, UK. 188pp

Law, F., 1956. The effects of afforestation upon the yield of water catchment areas. J. Brit. Waterworks Ass., 38, 489-494.

Law, F., 1958. Measurement of rainfall, interception and evaporation losses in a plantation of Sitka Spruce trees. Int. Assoc. of Sci. Hydrol. Publ., 44, Volume II, 397-411.

Lloyd, C.R., 1990. The temporal distribution of Amazonian rainfall and its implications for forest interception. Quart. J. Roy. Meteorol. Soc., 116, 1487-1494.

Maidment, D.R. (Ed.), 1992. Handbook of Hydrology. McGrawHill, New York, USA. 1424pp.

Meteorological Office, 1982. Observers Handbook. HMSO. London, UK. 220pp.

Meteorological Office, 2001. Rules for Rainfall Observers. Met. Office, Bracknell, UK. 12pp.

Newson, A.J. and Clarke R.T., 1976. Comparison of the catch of ground level and canopy level raingauges in the Upper Severn experimental catchment. Meteorol. Mag., 105, 2-7.

Oliver, H.R., 1974. Aerodynamic studies at Thetford forest. PhD Thesis. Department of Geophysics, University of Reading.

Price, D., 1999. Systematic error of standard UK raingauges in the central Scottish Highlands. Weather, 54, 334-341.

Robinson, A.C. and Rodda, J.C. 1969. Rain, wind and the aerodynamic characteristics of raingauges. Meteorol. Mag., 98, 113-120.

Rodda, J.C., 1968. The rainfall measurement problem. Int. Ass. Sci. Hydrol. Publ., 78, 215-31.

Rodda, J.C. and Smith, S.W., 1986. The significance of the systematic error in rainfall measurement for assessing wet deposition. Atmos. Environ., 20, 1059-1064.

Sevruk, B. and Klemm, S. 1989. Catalogue of National Standard Precipitation Gauges. Instruments and Observing Methods Report No 39. WMO/TD313. World Meteorological Organization. Geneva, Switzerland. 50pp.

Sevruk, B., Hertig, J.-A. and Spiess, R.. 1989. Wind field deformation above precipitation gauge orifices. Int. Ass. Hydrol. Sci. Publ., 179, 65-70.

van der Tol, Gash, J., Grant, S., McNeil, D. and Robinson, M., 2003. Average wet canopy evaporation for a Sitka spruce forest derived using the eddy correlation-energy balance technique. J. Hydrol., 276, 12-19.

WMO, 1994. Guide to hydrological practices, Report No 168 , World Meteorological Organization, Geneva, Switzerland. $735 \mathrm{pp}$. 